\title{
The Norwood procedure using a right ventricle-pulmonary artery conduit: Comparison of the right-sided versus left-sided conduit position
}

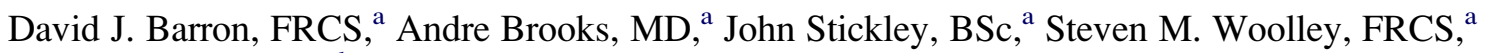

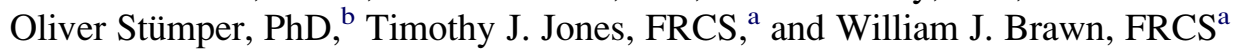

Objective: We proposed that a right-sided right ventricle-pulmonary artery conduit during the stage I Norwood procedure would facilitate pulmonary artery reconstruction during the stage II procedure.

\begin{abstract}
Methods: Between 2002 and 2006, 153 patients underwent Norwood stage I reconstruction with a right ventricle-pulmonary artery conduit (125 in the right-sided group and 28 in the left-sided group). The previous 150 consecutive classic Norwood procedures (1997-2002) were used as a control group. Outcomes from stages I and II were analyzed, including ventricular function and pulmonary artery morphology.
\end{abstract}

\begin{abstract}
Results: The 30-day survival was $88 \%(110 / 125)$ in the right-sided group, $75 \%(21 / 28)$ in the left-sided group, and $70 \%(105 / 150)$ in the control group $(P<.001$, right-sided vs control groups). The conduit length was $35 \pm 9$ $\mathrm{mm}$ in the right-sided group and $26 \pm 8 \mathrm{~mm}$ in the left-sided group $(P=.001)$. Survival at 6 months demonstrated a significant survival benefit in the right-sided right ventricle-pulmonary artery conduit group over the control group $(P=.009, \log$-rank test). There was no difference in ventricular function between the groups and no regional dyskinesia associated with the right ventricle-pulmonary artery conduit. Despite larger branch pulmonary artery size in the right ventricle-pulmonary artery conduit groups (compared with the control group), central pulmonary artery stenoses were common (62\% in the right conduit and $80 \%$ in the left conduit). Bypass and ischemic times at stage II were $49 \pm 10$ and $23 \pm 13$ minutes in the right-sided group compared with $61.5 \pm 9.5$ and $31 \pm 14$ minutes in the left-sided group $(P<.001$ and $P=.03$, respectively). The 30-day mortality after the stage II procedure was $1.3 \%(1 / 76)$ in the right-sided group, $0 \%(0 / 18)$ in the left-sided group, and $3.3 \%(3 / 90)$ in the control group.
\end{abstract}

Conclusion: The right-sided conduit is a safe technique and has improved 30-day and overall post-stage II survival compared with that seen with the classic Norwood procedure. The right ventricle-pulmonary artery conduit is associated with central pulmonary artery stenosis but good development of the branch pulmonary arteries and preservation of ventricular function. The right-sided conduit significantly reduces cardiopulmonary bypass times at stage II.

The Norwood procedure has undergone a variety of modifications since its introduction in $1981{ }^{1}$, and outcomes have steadily improved as a result of modifications of the surgical technique combined with better preoperative and postoperative management. ${ }^{2-5}$ In the recent era, the right ventriclepulmonary artery (RV-PA) conduit represents the single most important development in surgical technique. Although originally conceived by Norwood himself, ${ }^{6}$ the conduit was reintroduced by Sano and colleagues ${ }^{7}$ in 2001 and has become widely adopted because of evidence of

From the Departments of Cardiac Surgery ${ }^{\mathrm{a}}$ and Pediatric Cardiology, ${ }^{\mathrm{b}}$ Birmingham Children's Hospital, Birmingham, United Kingdom.

Read at the Eighty-eighth Annual Meeting of The American Association for Thoracic Surgery, San Diego, Calif, May 10-14, 2008.

Received for publication Sept 23, 2008; revisions received March 2, 2009; accepted for publication May 13, 2009; available ahead of print July 10, 2009.

Address for reprints: David J. Barron, FRCS, Consultant Cardiac Surgeon, Birmingham Children's Hospital, Steelhouse Lane, Birmingham B4 6NH, United Kingdom

(E-mail: david.barron@bch.nhs.uk).

J Thorac Cardiovasc Surg 2009;138:528-37

$0022-5223 / \$ 36.00$

Copyright (c) 2009 by The American Association for Thoracic Surgery

doi:10.1016/j.jtcvs.2009.05.004 improved hemodynamics and early outcomes. ${ }^{8-10}$ Proved benefits include higher diastolic blood pressure, prevention of retrograde diastolic flow in the aorta, and higher coronary perfusion pressure when compared with the classical Norwood procedure, in which the pulmonary blood supply is through a systemic-pulmonary artery (PA) shunt. There has also been evidence of improved growth of the central PAs at the time of the stage II procedure. ${ }^{10,11}$

This institution changed to the RV-PA conduit technique in 2002, routing the conduit to the leftward side of the neoaorta, according to previously described methods. ${ }^{7}$ Outcomes were encouraging, but at the time of the stage II operation, our institutional experience was that we found that the central PAs frequently required patch repair at the site of shunt insertion. This was a difficult and timeconsuming procedure because of the difficulty of mobilizing the PA behind the neoaorta and across into the left side.

To try and avoid this difficult dissection at stage II, we proposed a modification to the technique: routing the conduit to the right of the neoaorta (Figure 1), running into the right PA such that access to the distal shunt and PAs at stage II would be facilitated. 


\section{Abbreviations and Acronyms}

HLHS = hypoplastic left heart syndrome

$\mathrm{PA}=$ pulmonary artery

$\mathrm{RV}-\mathrm{PA}=$ right ventricle-pulmonary artery

The objective of this study was to analyze our experience with these modifications of the Norwood procedure. Outcomes were compared between the left-sided and right-sided conduits to test our hypothesis that routing the RV-PA conduit to the right of the neoaorta would facilitate PA reconstruction during the stage II procedure. The groups were compared with a matched group of patients undergoing classical Norwood procedures from the most recent cohort before the introduction of these modifications.

\section{MATERIALS AND METHODS}

All patients underwent the Norwood procedure for hypoplastic left heart syndrome (HLHS) or associated conditions at a single institution, the Diana Princess of Wales, Birmingham Children's Hospital NHS Trust, Birmingham, United Kingdom. The RV-PA conduit modification was first performed in March 2002, and all patients undergoing the Norwood procedure were included until the study end point in August 2006. During this period, 153 patients were identified from the hospital database and departmental records. Patients were divided into those receiving a rightsided conduit $(\mathrm{n}=125)$ and those receiving a left-sided conduit $(\mathrm{n}=28)$.

The preceding 150 consecutive classical Norwood procedures performed at this institution before the introduction of the RV-PA conduit were used as a comparative group. These were performed between February 1997 and March 2002. All patients undergoing the Norwood procedure were included in the study, and the anatomic subtypes and patient characteristics are listed in Table 1.

The study was a retrospective review that was registered with the Birmingham Children's Hospital R\&D department; ethical approval was applied for through the Central Office for Research Ethics Committees but was waived after consultation in respect of relying on retrospective, anonymized data. No patients were refused surgical intervention during the study period.

Data were collected from patients' records and from the departmental electronic database (Heartsuite; Systeria, Inc, Glasgow, United Kingdom). Preoperative characteristics were recorded as shown in Table 1. Operative data included bypass and ischemic times and are summarized in Table 2 . Interstage mortality was recorded together with the operative details and outcome of the stage II procedure. Follow-up was completed from patient records.

All patients underwent cardiac catheterization before the stage II procedure at 3 to 4 months of age. Angiograms were reviewed by one cardiologist $(\mathrm{OS})$ and one surgeon $(\mathrm{AB})$. The reviewers documented ventricular function (both global and segmental for areas of dyskinesia), central PA size, left and right PA size at the hilum (defined as the point immediately before the first branching point and expressed as a ratio of normal predicted values, according to published techniques ${ }^{10,12,13}$ ), grade of tricuspid regurgitation, and length of the conduit in the RV-PA groups. A significant PA narrowing was defined as a decrease in the predicted size of $25 \%$ or greater.

\section{Operative Technique}

Much of the details of the operative technique and arch reconstruction have been published previously. ${ }^{10}$ The techniques can be summarized as follows. Deep hypothermic cardiopulmonary bypass was used with an alpha-stat strategy, and antegrade cerebral perfusion has been used routinely during arch reconstruction since 2002. Myocardial protection was achieved with cold crystalloid cardioplegia $\left(30 \mathrm{~mL} \cdot \mathrm{kg}^{-1}\right)$. Arch reconstruction was performed with a pulmonary homograft patch after excision of all duct tissue and coarctation ridge (if present).

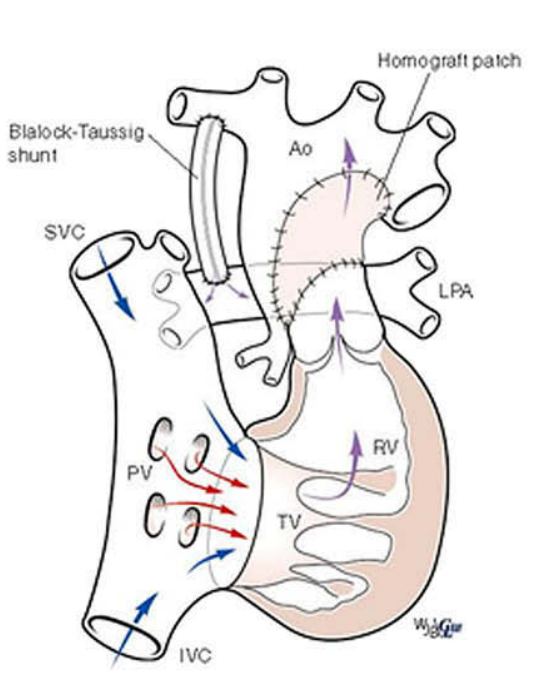

A

'Classical' Norwood

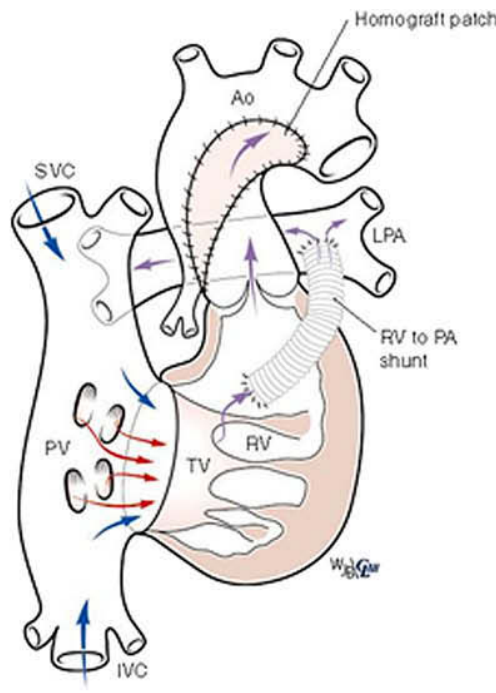

B Left RV-PA Conduit

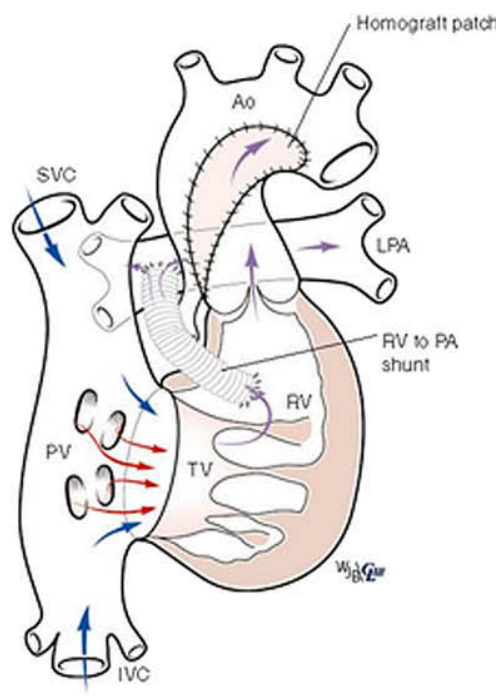

C Right RV-PA

FIGURE 1. Diagram showing the technical modifications of the Norwood procedure. A, The classical Norwood procedure with pulmonary blood supply through a right Blalock-Taussig shunt. B, The RV-PA conduit passing to the left of the neoaorta, as described by Sano and colleagues. ${ }^{7} \mathrm{C}$, The right ventriclepulmonary artery $(R V-P A)$ conduit passing to the right of the neoaorta. Ao, Aorta; $S V C$, superior vena cava; $L P A$, left pulmonary artery; $P V$, pulmonary vein; $R V$, right ventricle; $T V$, tricuspid valve; $I V C$, inferior vena cava; $P A$, pulmonary artery. Reproduced with permission from the Journal of Thoracic and Cardiovascular Surgery, 2006;131:418-26. 
TABLE 1. Patient characteristics

\begin{tabular}{|c|c|c|c|c|}
\hline & $\begin{array}{c}\text { Right-sided RV-PA } \\
\text { conduit }\end{array}$ & $\begin{array}{c}\text { Left-sided RV-PA } \\
\text { Conduit }\end{array}$ & $\begin{array}{c}\text { Control } \\
\text { (classical Norwood procedure) }\end{array}$ & $P$ value \\
\hline No. & 125 & 28 & 150 & - \\
\hline Age at Norwood procedure (d) & $4(3-7)$ & $6(4-12)$ & $4(3-7)$ & $.01 *$ \\
\hline Weight $(\mathrm{kg})$ & $3.1 \pm 0.6$ & $3.2 \pm 0.8$ & $3.2 \pm 0.6$ & NS \\
\hline BSA & $0.2(0.18-0.22)$ & $0.2(0.18-0.22)$ & $0.2(0.19-0.22)$ & NS \\
\hline Ascending aorta $(\mathrm{mm})$ & $3.0(2.0-4.0)$ & $3.2(2.0-5.0)$ & $3.2(2.5-4.5)$ & NS \\
\hline Impaired RV function $(\%)$ & 35.8 & 25 & 24.6 & NS \\
\hline Preoperative admission PICU (\%) & 50.4 & 57 & 57 & NS \\
\hline
\end{tabular}

*Patients were comparable in all aspects other than age, in which the left RV-PA group was a median of 2 days older. $R V-P A$, Right ventricle-pulmonary artery; $B S A$, body surface area; $R V$, right ventricular; $P I C U$, pediatric intensive care unit.

\section{Control Subjects (Classical Norwood Procedure)}

A 3.5-mm Gore-Tex shunt (W.L. Gore \& Associates (UK) Ltd, Livingston, Scotland) was used in neonates weighing $2.5 \mathrm{~kg}$ or more, and a $3-\mathrm{mm}$ shunt was used if weight was less than $2.5 \mathrm{~kg}$.

\section{RV-PA Conduits}

A 5 -mm Gore-Tex conduit was used in neonates weighing $2.5 \mathrm{~kg}$ or more, and a 4-mm conduit was used if weight was less than $2.5 \mathrm{~kg}$. The ventriculotomy was made in the infundibulum of the right ventricle in a vertical orientation for the left conduits and in a more diagonal-transverse orientation for the right conduits. The muscle edges were undermined to ensure a wide opening beneath the proximal shunt, which was anastomosed to the myocardium with a continuous 7-0 polypropylene suture (Figure 2).

For weaning from bypass, the inotrope delivery has changed during the period of the study from $10 \mu \mathrm{g} \cdot \mathrm{kg}^{-1} \cdot \mathrm{min}^{-1}$ dobutamine (until 2001) to $0.5 \mu \mathrm{g} \cdot \mathrm{kg}^{-1} \cdot \mathrm{min}^{-1}$ milrinone plus 0.05 to $0.2 \mu \mathrm{g} \cdot \mathrm{kg}^{-1} \cdot \mathrm{min}^{-1}$ epinephrine to maintain a systolic blood pressure of 60 to $70 \mathrm{~mm} \mathrm{Hg}$. A loading dose of milrinone was not used. Epicardial echocardiographic analysis was used routinely. The chest was routinely left open. The target arterial oxygen saturation was $70 \%$ to $80 \%$, with a mixed venous saturation of $40 \%$ to $50 \%$. Patients were discharged from the hospital on aspirin $\left(5 \mathrm{mg} \cdot \mathrm{kg}^{-1} \cdot \mathrm{d}^{-1}\right)$ and oral diuretic therapy. Patients with impaired right ventricular function or clinically important systemic atrioventricular valvar regurgitation also received an angiotensin-converting enzyme inhibitor.

Patients were electively catheterized at 12 to 15 weeks of age, with the aim of performing the second-stage procedure at 4 to 6 months of age. The exact timing was dependent on the patient's clinical progress and resting saturations. The second-stage procedure was a cavopulmonary shunt (bidirectional Glenn procedure). In the RV-PA conduit groups the conduit was ligated proximally but not excised from the heart.
Any significant narrowing ( $>25 \%$ from predicted size) in the central PAs was addressed at the time of the stage II procedure by using a pulmonary homograft patch.

\section{Statistical Methods}

Data have been examined by using the statistical software package $\mathrm{R}$ (version 2.4; R Foundation, Vienna, Austria). Continuous variables are expressed as means (standard deviations) or medians (ranges), and comparative univariable analyses have been made with the $t$ test, the Tukey multiple comparisons of means, or the Wilcoxon signed-rank test. Binomial or ordinal data are expressed as percentages, and comparative univariable analyses have been made with the 2-sided Fisher's exact test. A probability value of less than .05 was taken to represent a statistically significant difference between groups.

Actuarial survival was estimated by using the Kaplan-Meier productlimit method. These results have been expressed as probability estimates (standard errors of the mean). Univariable analyses of actuarial outcome measures have been made with the log-rank test.

\section{RESULTS}

In the entire patient group the mean weight was $3.2 \pm 0.6$ $\mathrm{kg}$, and the median age at the time of the operation was 4 days (interquartile range, 3-7 days). The mean ascending aortic size was $3.3 \pm 1.3 \mathrm{~mm}$. The groups were comparable in terms of patient characteristics. The patients in the left-sided group were slightly older at the time of the operation than those in the other groups (median, 6 vs 4 days), but weight and body surface area were comparable (see Table 1).

TABLE 2. Bypass details for the Norwood procedure and cavopulmonary shunt (stage II procedure) in the patient groups

\begin{tabular}{|c|c|c|c|c|}
\hline & Right-sided RV-PA conduit & Left-sided RV-PA conduit & $\begin{array}{c}\text { Control (classical } \\
\text { Norwood procedure) }\end{array}$ & $P$ value \\
\hline \multicolumn{5}{|l|}{ Norwood procedure } \\
\hline $\mathrm{CPB}(\min )$ & $116 \pm 23$ & $106 \pm 26$ & $81 \pm 37$ & $<.01$, control vs RV-PA group* \\
\hline $\mathrm{AXC}(\min )$ & $58 \pm 16$ & $56 \pm 14$ & $53 \pm 14$ & NS \\
\hline DHCA (min) & $20 \pm 16$ & $22 \pm 16$ & $51 \pm 14$ & $<.01$, control vs RV-PA group \\
\hline \multicolumn{5}{|l|}{ Stage II procedure } \\
\hline $\mathrm{CPB}(\min )$ & $49 \pm 12$ & $61 \pm 9$ & $48 \pm 19$ & $\begin{array}{l}<.001 \text {, right-sided vs left-sided group } \\
<.001 \text {, control vs left-sided group }\end{array}$ \\
\hline $\mathrm{AXC} / \mathrm{DHCA}(\mathrm{min})$ & $23 \pm 13$ & $31 \pm 14$ & $19 \pm 11$ & $\begin{array}{l}<.03 \text {, right-sided vs left-sided group } \\
<.01, \text { control vs left-sided group }\end{array}$ \\
\hline
\end{tabular}

*The difference in CPB times is accounted for by the introduction of antegrade cerebral perfusion in the RV-PA conduit groups. If the cerebral perfusion times are incorporated into the data, the difference ceases to be significant. $R V-P A$, Right ventricle-pulmonary artery; $C P B$, cardiopulmonary bypass time; $A X C$, aortic crossclamp time; $D H C A$, deep hypothermic cardiac arrest time. 


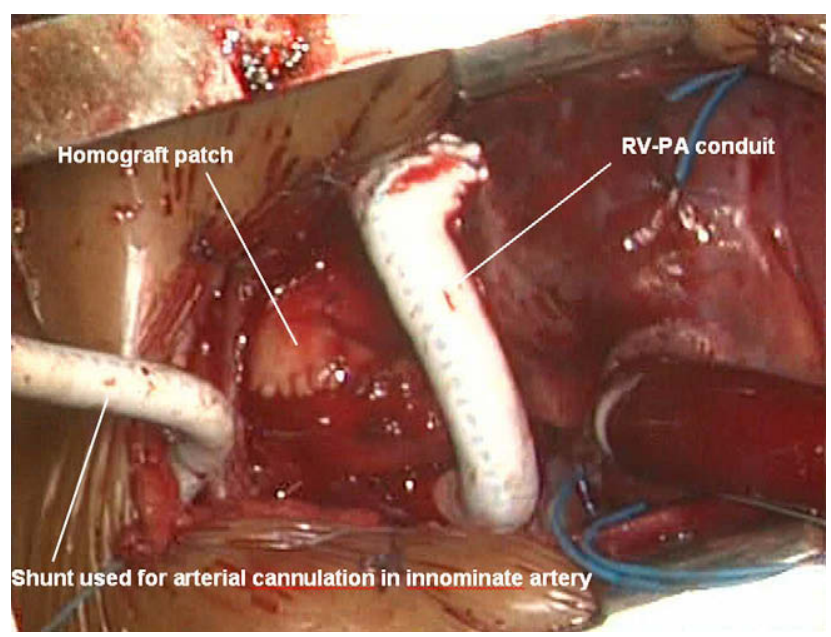

FIGURE 2. Operative photograph of the right-sided right ventriclepulmonary artery $(R V-P A)$ conduit. The arch reconstruction and conduit have been completed. The venous cannula is still in place in the right atrium, and the arterial cannulation is through a 3-mm Gore-Tex shunt anastomosed to the innominate artery.

Two hundred ninety-one (96.4\%) of 304 patients had variants of HLHS, including 5.5\% (16/291) with unbalanced atrial ventricular septal defects with right ventricular dominance. A few $(3.6 \%)$ of the patients had a Norwood procedure for complex forms of right ventricular hypoplasia (transposition of the great arteries with tricuspid atresia and hypoplastic aorta and double-inlet left ventricle with transposition of the great arteries), but there was no difference in the proportion of these patients between groups. None of the patients in the ventricle-PA conduit groups had a left ventriculotomy, with the conduit always being taken from the right ventricle.

The bypass details are shown in Table 2 for both the stage I and stage II procedures. The data for the stage I procedures should be interpreted with respect to the fact that antegrade cerebral perfusion was introduced in March 2002. Thus the period of cardiopulmonary bypass was longer, and the deep hypothermic circulatory arrest during arch reconstruction was significantly reduced as a consequence of this. When cerebral perfusion times were added into the analysis (artificially adding them onto the DCHA time), then the differences ceased to be significant. However, the total crossclamp time was slightly greater in the RV-PA conduit groups than in control group because of the additional period required for the creation of the proximal conduit anastomosis $(P=.05)$.

Overall 30-day survival for the Norwood procedure in this study was $77.8 \%$. The 30 -day survival was $88 \%(110 / 125)$ in the right-sided group, $75 \%(21 / 28)$ in the left-sided group, and $70 \%(105 / 150)$ in the control group $(P<.001$, rightsided vs control groups).

The length of the RV-PA conduit was $35 \pm 9 \mathrm{~mm}$ in the right-sided group and $26 \pm 8 \mathrm{~mm}$ in the left-sided group

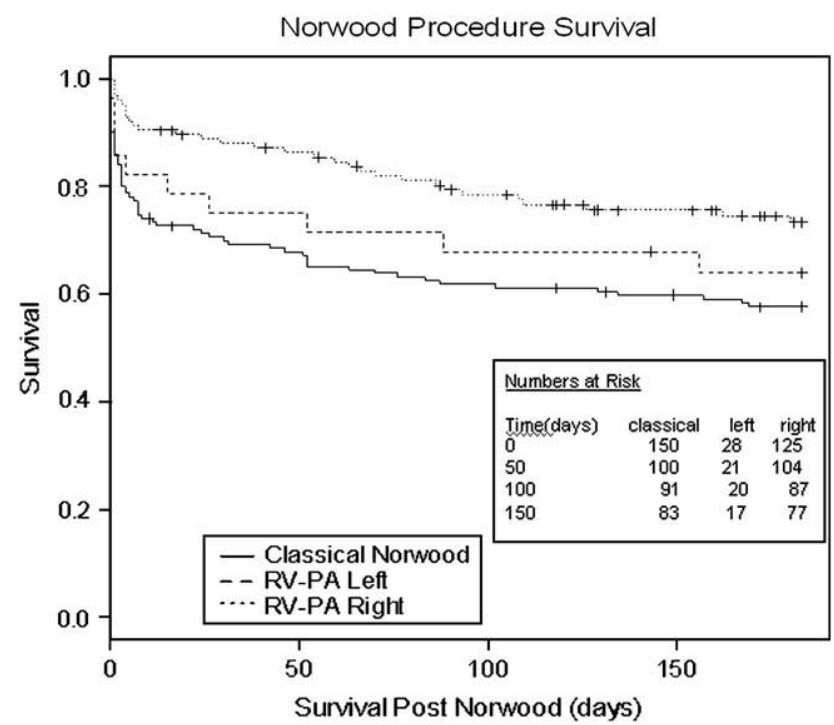

FIGURE 3. Kaplan-Meier survival curves after the Norwood procedure performed with the classical technique (right modified Blalock-Taussig shunt) or with a left- or right-sided right ventricle-pulmonary artery $(R V-$ $P A)$ conduit. The right-sided RV-PA conduit group had significantly better survival at 30 days and 6 months $(P=.009)$ when compared with those undergoing the classical Norwood procedure.

$(P=.001)$. There was no difference in mean saturations $(79 \% \pm 7 \%$ vs $77 \% \pm 10 \%)$ at the time of catheterization between the classical and RV-PA conduit groups.

Follow-up was $100 \%$ complete over a median period of 15.7 months (range, $0.3-122$ months). Of the 236 survivors of the stage I procedure, 195 underwent the stage II procedure, and a further 5 are awaiting the stage II procedure. Interstage mortality was $11.8 \%$ overall. Within the study groups, the interstage mortality was $14 \%$ in the right-sided group, $11 \%$ in the left-sided group, and $10 \%$ in the control group.

The overall pre-stage II survival was $74 \%(92 / 125)$ in the right-sided group, $64 \%(18 / 28)$ in the left-sided group, and $60 \%(90 / 150)$ in the control group $(P=.02$, right-sided vs control groups). Kaplan-Meier actuarial survival curves are shown in Figure 3. Although all groups demonstrated interstage mortality, the survival benefit of the right-sided RVPA conduit seen after 30 days was maintained throughout the study period. Regression analysis for the right-sided group showed improved survival over the classical Norwood procedure $(P=.009$, control group) at 6 months. There was no difference demonstrable between the left-sided RV-PA conduit group and the control group.

A total of 130 pre-stage II angiograms underwent detailed review, and only those performed at other institutions were excluded. There was no difference in the proportion from each group studied.

Ventricular function was normal or mildly impaired in $85.9 \%(59 / 65)$ of the right-sided group, $76.4 \%(13 / 17)$ of the left-sided group, and $85.2 \%$ (40/47) of the control group. 

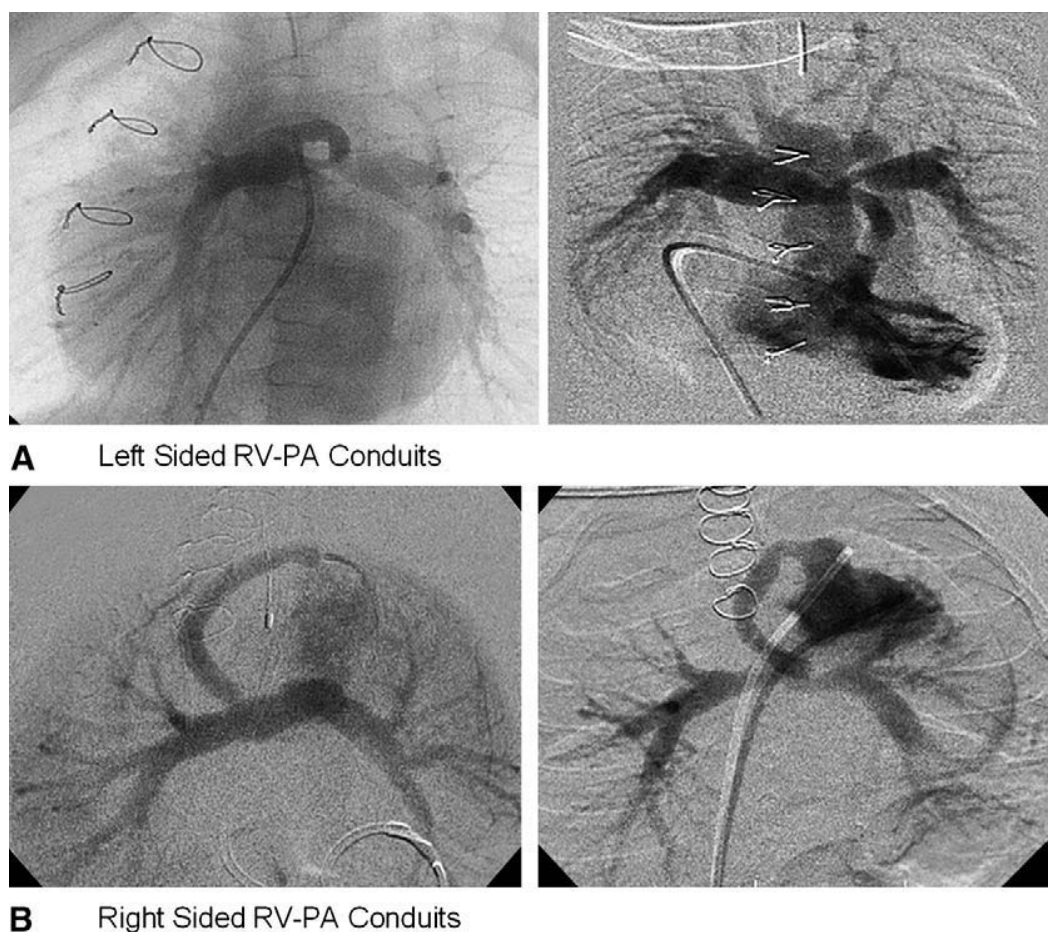

FIGURE 4. Angiogram still images after the stage I Norwood procedure showing the right ventricle-pulmonary artery $(R V-P A)$ conduits and pulmonary arteries. A, Examples of the left-sided conduit. Central pulmonary artery stenoses were common and required patching at stage II in $83 \%$. B, Examples of the right-sided conduits. Central stenoses (see image on the right) were common, although access from the right side was facilitated by the shunt position. Note that the right-sided conduits take a longer course than the left-sided conduits.

This difference was not statistically significant $(P=.07)$. There was no evidence of regional wall dyskinesia (specifically of the anterior free wall) associated with the RV-PA conduit groups. Examples of the angiograms are shown in Figure 4.

PA sizes are summarized in Figure 5. Any diameter of less than $25 \%$ of predicted size was regarded as significant. Central PA narrowing was commonly seen in both the RV-PA conduit groups (mean diameter of $0.65 \pm$ 0.29 in the left-sided group and $0.75 \pm 0.41$ in the right-sided group compared with $1.2 \pm 0.31$ in the control group, $P<.001)$. Although the incidence of narrowing was slightly worse in the left-sided group $(80 \%$ vs $62 \%$ ), there was no significant difference between those of the right- and left-sided groups.

In contrast, the branch PA sizes were larger in the RV-PA conduit groups than in the control group (2.51 and 2.52 for the RV-PA conduit groups vs 2.31 for the control group, $P<.01$ ), with the greatest benefit seen in the left PA (1.27 and $1.19 \mathrm{vs}$ 1.01 , respectively; $P<.01$ ). Again there was no difference between the 2 RV-PA conduit groups; both had larger branch PAs than the control group (Figure 5, $A$ and $B$ ).

The stage II procedure was performed at a median age of 22 weeks (interquartile range, 18-26 weeks). Outcome from the stage II procedure was similar in all groups. There was no incidence of shunt injury at resternotomy, and all patients were started on bypass in a routine fashion. The 30-day mortality was $1.3 \%(1 / 76)$ in the right-sided group, $0 \%(0 / 18)$ in the left-sided group, and 3.3\% (3/90) in the control group. The single death in the RV-PA conduit groups was of a patient with severe tricuspid regurgitation and an impaired right ventricle. Ventricular function remained impaired postoperatively, with high PA pressures, and the patient could not weaned from ventilatory support despite reversing the cavopulmonary shunt on day 17.

Narrowed central PAs were enlarged with a patch of pulmonary homograft at the time of the stage II procedure, where necessary. The majority of the patients receiving RV-PA conduits required patching, as defined above. Cardiopulmonary bypass time was $49 \pm 12$ minutes in the right-sided group compared with $61 \pm 9$ minutes in the left-sided group and $48 \pm 29$ minutes in the control group $(P<.005$, right-sided vs left-sided groups). Ischemic times (combined aortic crossclamping and deep hypothermic circulatory arrest) were also significantly longer in the left RV-PA conduit group ( $31 \pm 14$ minutes vs $23 \pm 13$ minutes in the right-sided group and $19 \pm 11$ minutes in the control group, $P<.01$ ).

Survival curves at 6 months after the stage I Norwood procedure demonstrate a survival benefit in the RV-PA group compared with those undergoing the classic Norwood procedure $(P=.009, \log$-rank test $)$. 

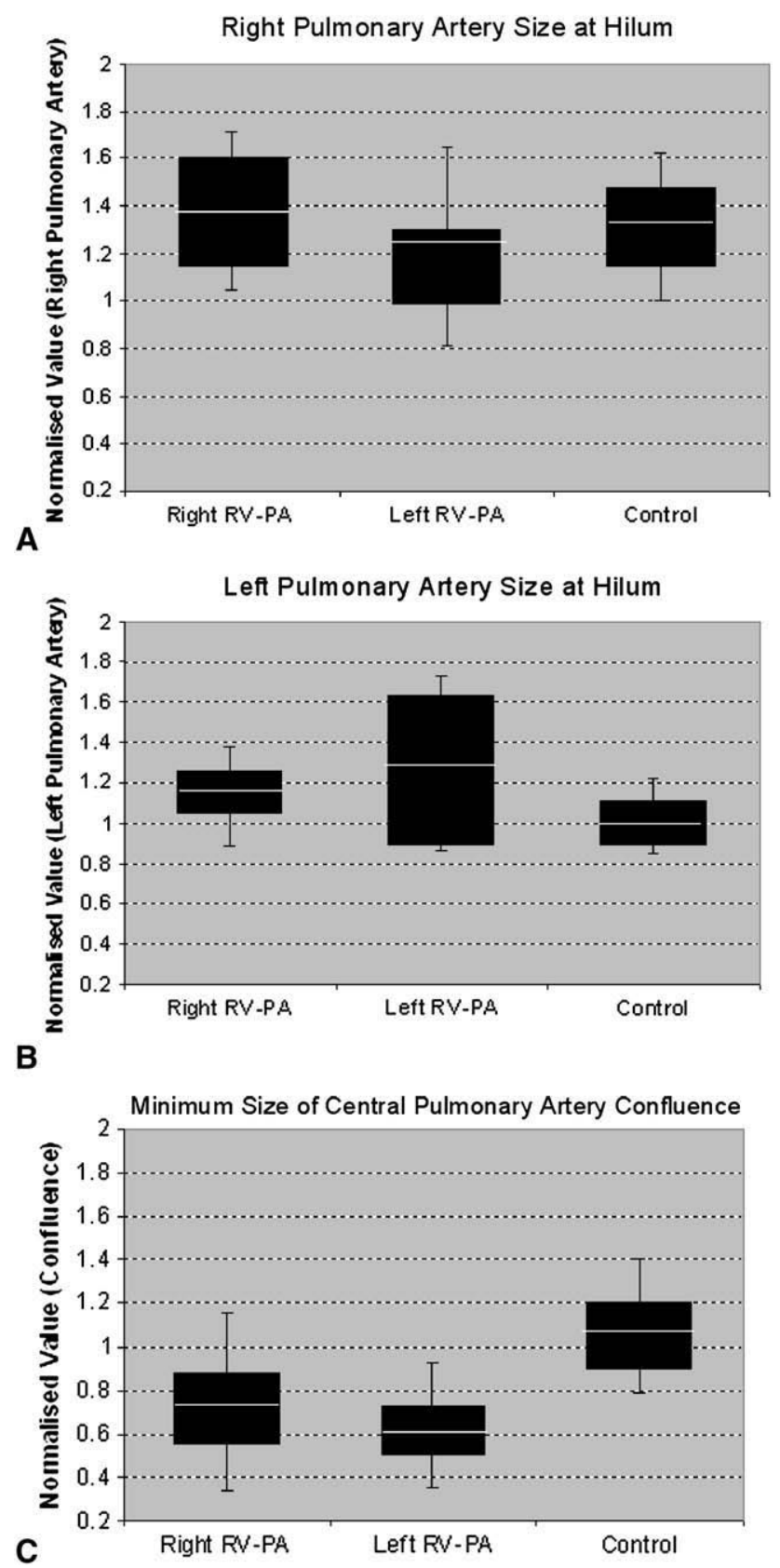

FIGURE 5. Box plots showing the distribution of pulmonary artery size in the 3 groups of patients at the time of the stage II procedure. Each box represents the interquartile range, and the solid line in each box shows the mean value. All values were expressed as a normalized value according to the patients' weight and body surface area. A, Right pulmonary artery sizes. There was no difference between groups. B, Left pulmonary artery sizes. Both right ventricle-pulmonary artery $(R V-P A)$ conduit groups had larger left pulmonary arteries than the control group $(P<.01)$. There was no difference between the 2 RV-PA conduit groups. C, Narrowest diameter of confluence. Both RV-PA conduit groups had a greater degree of central stenosis than the control group $(P<.01)$. There was no difference between the 2 RV-PA conduit groups.

\section{DISCUSSION}

The RV-PA conduit has attracted a great deal of interest as a technical modification of the classical Norwood procedure. The concept was originally proposed by Dr Norwood himself in the 1980s, but no suitable conduits were believed to be available. ${ }^{6}$ The advantage of providing PA flow through an RV-PA conduit rather than with a systemic shunt has been shown to be the maintenance of systemic diastolic pressure, reducing reversed aortic flow during the diastolic phase. ${ }^{8-10,14}$ However, concerns with the technique include the need for a ventriculotomy with consequent impairment of ventricular function and a risk of ventricular arrhythmias. Graham and colleagues ${ }^{11}$ recently compared ventricular function in patients receiving an RV-PA conduit and those undergoing the classical Norwood procedure and could not demonstrate any difference. These findings support those described in this study in that we could find no difference in global right ventricular function or in anterior wall motion within the RV-PA groups and the control group. A second potential problem with the RV-PA conduit is that there is also a degree of regurgitation that might volume load the ventricle. This has already led to the consideration of the use of small homografts to provide a competent valve as the RV-PA conduit. ${ }^{15}$

As a consequence of these arguments, the RV-PA conduit has not been adopted universally. The debate is further complicated by parallel advances in operative and perioperative management, which continue to improve the outcomes of the procedure. These have included changes in bypass techniques, such as the introduction of antegrade cerebral perfusion during arch repair (although this has still not always been shown to influence survival outcomes), and a trend toward smaller shunt sizes to protect against pulmonary overcirculation. ${ }^{16,17} \mathrm{~A}$ shift of focus from manipulating the pulmonary vascular resistance to the sustained reduction in systemic vascular resistance has also improved postoperative management, ${ }^{3,5}$ and it has been difficult to measure the effect of each of these individual factors on the improving overall outcomes of the past few years., ${ }^{3,18}$

We previously reported our early experience with the RV-PA conduit and demonstrated a survival benefit in comparison with the classical procedure at our institution. ${ }^{12}$ However, when assessing left-sided RV-PA conduits for the stage II procedure, there was frequently significant central narrowing in the PAs. This resulted in the stage II operation requiring considerable mobilization and surgical dissection over to the leftward side. ${ }^{10}$

Difficulties with the stage II procedure have not been a major feature of recent publications, although most have focused on events surrounding the first stage. However, outcomes from the stage II procedure have not been without incident ( $8 \%$ mortality in Sano and colleagues' original series $^{4}$ ), and the need for extensive leftward mobilization of 
the PAs has been frequently recognized (personal communication). Ballweg and coworkers ${ }^{19}$ recently described a $58 \%$ incidence of central PA stenoses and hypoplasia associated with the left-sided RV-PA conduit. It was for this reason that we proposed bringing the RV-PA conduit to the right of the reconstructed aorta to make access to the shunt and PAs much easier at stage II and avoid the need to have to approach the PAs to the left of the neoaorta. A rightward course of the conduit has been cited recently by other authors, ${ }^{20}$ but the 2 variants have not previously been compared.

The results confirm that the right shunt significantly reduced the bypass and ischemic times for the stage II procedure. From a surgeon's viewpoint, any reconstruction of the PAs was far more accessible and easier to perform. The PAs themselves developed very well in all the RVPA conduit groups and support our previous observations that the technique is associated with excellent branch PA growth, particularly of the left PA, which can become relatively hypoplastic in the setting of a classical shunt procedure. Although the size of the branch PAs alone is only one of many factors that influence outcome with the Fontan circulation, this is certainly an important consideration in the Norwood procedure and something that can be influenced by surgical technique. It is encouraging that the right-sided RV-PA conduit was associated with similar improved development of the left PA, despite the position of the shunt being somewhat more distant from the left lung. Patch augmentation of the central PAs was still frequently required ( $62 \%$ to $80 \%$ of cases), but access was straightforward from the right side.

The unexpected finding in this study was the survival benefit of the right-sided conduit over the original, left-sided Sano conduit. There were no differences in terms of bypass and ischemic times. The only technical difference that we demonstrated was that the right-sided conduit is naturally longer than when placed to the left (a mean of $9 \mathrm{~mm}$ longer), which would provide a greater fixed resistance to pulmonary blood flow and also reduce the regurgitant fraction imposed on the right ventricle. The data do not permit any further analysis of the shunt characteristics, and these are only speculative reasons as to why this might have a hemodynamic advantage. We have not demonstrated any difference in arterial oxygen saturation between the left- and right-sided groups, but this has been shown to be a poor indicator of Qp in the setting of the Norwood circulation, where systemic oxygen delivery (Qs) and oxygen extraction might have a more important role. ${ }^{18}$ Sternal re-entry was not hazardous, despite the anterior position of the proximal conduit. This was partly helped by the routine placement of a Gore-Tex pericardial membrane at the time of chest closure after the stage I procedure.

One of the greatest concerns regarding these outcomes is the consistent attrition between hospital discharge after the stage I procedure and completion of the stage II procedure.
Interstage mortality has been a feature of most programs for HLHS in which interstage mortality has commonly ranged between $9 \%$ and $16 \% .^{3,5,21,22}$ The cause of interstage mortality has not been fully elucidated, and a substantial proportion remains sudden and unexpected. ${ }^{23}$ Ghanayem and colleagues ${ }^{24}$ reported complete interstage survival after the introduction of a "home surveillance program" that enabled at-risk patients to be identified and treated aggressively. Home monitoring of pulse oximetry and close inpatient surveillance have both been suggested to reduce risk and been shown to be successful. A detailed analysis of the interstage deaths might help identify risk factors but was beyond the scope of this study; nevertheless, the sustained survival benefit of the RV-PA conduit beyond stage II remains an important observation.

The retrospective design of this study limits the power of any inferences that are made regarding the superiority of one technique over another. It is possible that the results of the left-sided conduit would have improved with experience if the technique had been continued. The data cannot answer this, but the evidence that even the left-sided group showed an immediate improvement ${ }^{25}$ over the classical group would suggest that technical issues were not a major factor. The improved survival could equally be interpreted as being due to the effect of era on outcomes, but we believe this is unlikely in view of the stepwise change in mortality seen with introduction of the RV-PA conduit. Our previous studies of Norwood outcomes have not suggested that era was a strong factor in outcome. ${ }^{12}$ The technique is an example of one modification spawning another, the danger being that too many options make it increasingly difficult to verify and analyze individual techniques. As we await the results of a randomized trial of the classical versus RV-PA conduit, this article potentially adds a new variation for consideration. We can only argue that surgical intervention for HLHS is a constantly evolving field in which rapid advances are being made but in which there is still no standard management and in which problems have to be dealt with as they arise.

In conclusion, the RV-PA conduit is a safe technique that does not seem to impair ventricular function and that confers a survival benefit up to at least 6 months of life after Norwood stage I reconstruction. The right-sided conduit facilitates repair at stage II and appears to confer a survival benefit after the stage I procedure over that seen after the classical Norwood procedure that we could not demonstrate with the left-sided conduit. This might be related to the longer length of the conduit used. A high incidence of central PA stenosis occurred with the RV-PA conduits, but PA reconstruction at stage II is greatly facilitated if the RVPA conduit is routed to the right of the neoaorta.

We thank Drs Simon McGuirk and Elizabeth Rumball for their help with the data collection and Dr Paul Davies for statistical advice. 


\section{References}

1. Norwood WI, Lang P, Hansen DD. Physiologic repair of aortic atresia-hypoplastic left heart syndrome. $N$ Engl J Med. 1983;308:23-6.

2. Pizarro C, Malec E, Maher KO, Januszewska K, Gidding SS, Murdison KA, et al. Right ventricle to PA conduit improves outcome after stage I Norwood for hypoplastic left heart syndrome. Circulation. 2003;108:II155-60.

3. Tweddell JS, Hoffman GM, Mussatto KA, Fedderly RT, Berger S, Jaquiss RD, et al. Improved survival of patients undergoing palliation of hypoplastic left heart syndrome: lessons learned from 115 consecutive patients. Circulation. 2002;106: I82-9.

4. Sano S, Ishino K, Kawada M, Honjo O. Right ventricle-pulmonary artery shunt in first-stage palliation of hypoplastic left heart syndrome. Semin Thorac Cardiovasc Surg Pediatr Card Surg Annu. 2004;7:22-31.

5. Azakie T, Merklinger SL, McCrindle BW, Van Arsdell GS, Lee KJ, Benson LN, et al. Evolving strategies and improving outcomes of the modified Norwood procedure: a 10-year single-institution experience. Ann Thorac Surg. 2001;72: 1349-53.

6. Norwood WI, Lang P, Casteneda AR, Campbell DN. Experience with operations for hypoplastic left heart syndrome. J Thorac Cardiovasc Surg. 1981; 82:511-9.

7. Sano S, Ishino K, Kawada M, Arai S, Kasahara S, Asai T, et al. Right ventriclepulmonary artery shunt in first-stage palliation of hypoplastic left heart syndrome. J Thorac Cardiovasc Surg. 2003;126:504-9.

8. Maher KO, Pizarro C, Gidding SS, Januszewska K, Malec E, Norwood WI Jr, et al. Hemodynamic profile after the Norwood procedure with right ventricle to pulmonary artery conduit. Circulation. 2003;108:782-4.

9. Malec E, Januszewska K, Kolcz J, Mroczek T. Right ventricle-to-pulmonary artery shunt versus modified Blalock-Taussig shunt in the Norwood procedure for hypoplastic left heart syndrome-influence on early and late haemodynamic status. Eur J Cardiothorac Surg. 2003;23:728-33.

10. Rumball EM, McGuirk SP, Stumper O, Laker SJ, de Giovanni JV, Wright JG, et al. The RV-PA conduit stimulates better growth of the pulmonary arteries in hypoplastic left heart syndrome. Eur J Cardiothorac Surg. 2005;27:801-6.

11. Graham EM, Atz AM, Bradley SM, Scheurer MA, Bandisode VM, Laudito A, et al. Does a ventriculotomy have deleterious effects following palliation in the Norwood procedure using a shunt placed from the right ventricle to the pulmonary arteries? Cardiol Young. 2007; 17:145-50.

12. Li J, Zhang G, McCrindle BW, Holtby H, Humpl T, Cai S, et al. Profiles of hemodynamics and oxygen transport derived by using continuous measured oxygen consumption after the Norwood procedure. J Thorac Cardiovasc Surg. 2007;133:441-8.

13. McGuirk SP, Stickley J, Griselli M, Stumper OF, Laker SJ, Barron DJ, et al. Risk assessment and early outcome following the Norwood procedure for hypoplastic left heart syndrome. Eur J Cardiothorac Surg. 2006;29:675-81.

14. Tatum GH, Sigfússon G, Ettedgui JA, Myers JL, Cyran SE, Weber HS, et al. Pulmonary artery growth fails to match the increase in body surface area after the Fontan operation. Heart. 2006;92:511-4.

15. Edwards L, Morris KP, Siddiqui A, Harrington D, Barron D, Brawn W. Norwood procedure for hypoplastic left heart syndrome: BT shunt or RV-PA conduit? Arch Dis Child Fetal Neonatal Ed. 2007;92:F210-4.

16. Reinhartz O, Reddy VM, Petrossian E, MacDonald M, Lamberti JJ, Roth SJ, et al. Homograft valved right ventricle to pulmonary artery conduit as a modification of the Norwood procedure. Circulation. 2006;114(suppl):I594-9.

17. Pigula FA. Arch reconstruction without circulatory arrest: scientific basis for continued use and application to patients with arch anomalies. Semin Thorac Cardiovasc Surg Pediatr Card Surg Annu. 2002;5:104-15.

18. Kitaichi T, Chikugo F, Kawahito T, Hori T, Masuda Y, Kitagawa T. Suitable shunt size for regulation of pulmonary blood flow in a canine model of univentricular parallel circulations. $J$ Thorac Cardiovasc Surg. 2003;125:71-8.

19. Ballweg JA, Dominguez TE, Ravishanker C, Kreutzer J, Marino BS, Bird GL, et al. A contemporary comparison of the effect of shunt type in hypoplastic left heart syndrome on the haemodynamics and outcome at stage 2 reconstruction. J Thorac Cardiovasc Surg. 2007;134:297-303.

20. Aortic atresia and hypoplastic left heart syndrome. In: Litwin SB, ed. Color atlas of congenital heart surgery. 2nd ed. New York: Springer Publishing; 2007.p.402-14.

21. Pearl JM, Nelson DP, Schwartz SM, Manning PB. First-stage palliation for hypoplastic left heart syndrome in the twenty-first century. Ann Thorac Surg. 2002;73: 331-9.

22. Gaynor JW, Mahle WT, Cohen MI, Ittenbach RF, DeCampli WM, Steven JM, et al. Risk factors for mortality after the Norwood procedure. Eur J Cardiothorac Surg. 2002;22:82-9.
23. Mahle WT, Spray TL, Gaynor JW, Clark BJ 3rd. Unexpected death after reconstructive surgery for hypoplastic left heart syndrome. Ann Thorac Surg. 2001; 71:61-5.

24. Ghanayem NS, Hoffman GM, Mussatto KA, Cava JR, Frommelt PC, Rudd NA, et al. Home surveillance program prevents interstage mortality after the Norwood procedure. J Thorac Cardiovasc Surg. 2003;126:1367-77.

25. McGuirk SP, Griselli M, Stumper OF, Rumball EM, Miller P, Dhillon R, et al Staged surgical management of hypoplastic left heart syndrome: a single institution 12 year experience. Heart. 2006;92:364-70.

\section{Discussion}

Dr Shunji Sano (Okayama City, Japan). I congratulate Dr Barron and his group on their excellent results. They presented the results of first-stage palliation of HLHS. Their experience with 153 patients over a 4.5 -year period shows a 30 -day mortality of $12 \%$ on right-sided RV-PA, $25 \%$ on the left side, and $30 \%$ in the control group. They also demonstrated a significant survival benefit in the RV-PA group. No difference in ventricular function was seen between groups. No regional dyskinesia was associated with the RV-PA shunt. Central PA stenosis has the advantage of an RV-PA shunt, especially on the left side.

Since 1998, 61 consecutive patients underwent RV-PA shunts in our unit, and all patients had a left-sided RV-PA shunt. Our 30 -day mortality is $6.6 \%$, and 6-month mortality is $10 \%$. Fortyseven patients underwent the bidirectional Glenn procedure, and PA plasty was required in 17 patients. Fourteen patients underwent Hegar dilation only through a bidirectional Glenn anastomosis site. Only 3 patients required patch angioplasty. Twenty-nine patients have reached Fontan compression, with 8 patients requiring PA plasty. Some of them had Hegar dilation only, and only 1 patient required patch aortoplasty. Therefore of 61 patients, only 4 required patch aortoplasty, and all 4 patients had reconstructed distal PA stumps with autologous pericardium.

Therefore we changed our technique of distal PA anastomosis by using a polytetrafluoroethylene cuff graft, which is already reported. Since then, we have had no patients who required PA patch aortoplasty.

As long as pulmonary blood flow is through an RV-PA shunt, theoretically, there is not much difference if the shunt is right or left sided. The reasons why I do RV-PA shunts to the left side are that a left-sided shunt looks natural, it does not cross the aorta, and the RV-PA shunt could be left open at the time of the bidirectional Glenn procedure as additional flow if the PA is small, especially the left side.

I have a few questions for Dr Barron. First, I think everyone is worried about compression of the graft if the graft crossed the neoaorta. Did you find any stenosis or obstruction in the graft?

Dr Barron. Thank you very much, Dr Sano. I should be standing here congratulating you over your results, too.

I think that you make a very valid point. All we can say is that we have not encountered it as being a major problem because I think it concerned us, too. We used delayed sternal closure, and we would not close the chest until a patient had been in a persistent negative fluid balance so that any of the original cardiac swelling had disappeared. Therefore we were not seeing acute obstruction to the shunt when the chest was closed. 
In terms of follow-up, we have only been conscious of seeing it in 2 of 125 patients who have had the RV-PA shunt inserted, and those 2 patients have both been treated with a coronary stent placed at the time of catheterization to just buy extra time until the operation. Therefore I cannot say that we have been conscious of it being a major issue with the patients.

Whether some of the interstage mortality was related, it is very difficult for us to analyze interstage death, which is very frustrating, but the histories of the patients would not suggest a thrombosis of the shunt.

Dr Sano. In your article a central PA stenosis was $80 \%$ at the left side and $62 \%$ at the right side. To me, the late or center pulmonary stenosis is quite different from our experience. Could you describe your technique of left-sided PA reconstruction. Also, you anastomosed a shunt directly to the PA still with significant PA stenosis. Therefore did you change your technique of distal PA anastomosis to avoid PA stenosis?

Dr Barron. We certainly recognize that we are seeing a high incidence of PA stenosis and that it has not been reported by everybody, and we do not quite understand why that should be.

Clearly, I think other centers have experienced this problem with the PAs, and we can say that we are certainly aware of centers who regard it as such a significant problem that they have reverted back to doing the classical Norwood procedure because they were finding it difficult to manage these cases.

In terms of whether we changed our technique, we did try changing. We tried putting a patch first into the PAs and then putting a shunt into the patch or putting the shunt directly into the PAs. But we could not demonstrate any improvement. Although there is a very high incidence of narrowing in the PA, many are only relatively narrow. I am not sure whether everybody would consider them meriting too much attention, but we would regard anything more than a $25 \%$ reduction in diameter as requiring attention at the time of the operation.

In terms of our technique for doing it, we would open the artery as far as we could out into the hilum of the lung and repair it with a PA patch.

Dr Sano. Finally, we reported that regurgitant flow ratio through a 5 -mm graft is $26 \%$ by using color Doppler echocardiographic analysis. Did you measure regurgitant flow ratio in your series, and was there any difference in the right-sided and left-sided shunts?

Dr Barron. The simple answer is that we did not, but it would be very interesting to know that. Because, as you say, it might be that some of the advantage of that longer shunt is that it reduces the regurgitant fraction because the back resistance is that little bit higher. But we did not measure it.

Dr Sano. I will just mention that the RV-PA shunt procedure started only 9 years ago, and with refinement of the procedure, the result has been proved in many institutions. I must say the PA reconstruction is not easy, and we need more refinement.

Finally, I congratulate your excellent results and beautiful presentation, and I must thank the association for giving me the opportunity to discuss this important article.

Dr Ardawan Rastan (Leipzig, Germany). I appreciate your presentation very much, and it was really interesting. You have a huge experience in these really demanding patients.

I have 2 questions. First, do you have any experience with valved conduits? Second, do you have any experiences with or do you have any problems with reoperations for stage II? Do you have any injuries of the shunts, and do you have any protocols to avoid any adhesions for these patients?

Dr Barron. We do not use valved conduits. I would be very interested to see Dr Hanley's series recently published using small homografts in these patients, and certainly you could see the hemodynamic benefits that might have. The simple truth is that we do not have access to this type of small homograft in sufficient numbers that we could use valved conduits, and therefore we have not.

We have not had any problem in resternotomy in these patients. It worried us going straight in with the conduit being very anterior. I think the use of a pericardial Gore-Tex membrane has been very helpful, but we have not had a single episode of injuring a heart on reopening the sternum, and all the patients were started on bypass in a routine fashion.

Dr James S. Tweddell (Milwaukee, Wis). Thanks, this was an excellent study and an excellent presentation.

I think we actually do this in a way very similar to your technique. We also bring the conduit to the right side. I think the difference-and this might be important - is that we routinely patch the distal pulmonary confluence. I also fully mobilize the PAs from first branch to first branch to place the native PA segment actually to the right of the ascending aorta as well.

I think that this was brought up as a potential factor last week at the World Society of Pediatric and Congenital Heart Surgery. I do not always remember who the author was, Jeff. Therefore it might be that patching and the right-sided position are important. But I thought your article was excellent and I just rise to add those 2 potential comments of ways to modify the technique.

My question is concerning your stage II strategy. Do you routinely clamp for that, and what is the need for that?

Dr Barron. Thank you.

In terms of patching the PAs, I am intrigued by patching the PAs because it seems to make sense that we should be patching them all. But when we analyzed this-we published our data last year simply looking at patching the PAs at the time of the stage I procedure (it was in a more historical cohort before the RV-PA conduits)—we could not demonstrate that patching them or not patching them, by closing the PAs directly, seemed to have any influence on the morphology of the PAs afterward. We cannot really explain that. I wonder whether there is such limited room sometimes in the concavity of the arch underneath the reconstructed aorta that the left PA gets kind of trapped a little behind it and whether sometimes putting a patch in simply leaves you too much tissue in there and the thing just gets folded and caught between it.

Dr Tweddell. Well, I think you should put the distal conduit into the patch.

Dr Barron. Into the patch. That might be a good point. And you had a second question?

Dr Tweddell. Concerning the stage II procedure.

Dr Barron. It has been our policy_and that might be a rather aggressive policy - that we tend to cool the patients right down at stage II unless they have very straightforward anatomy and have routinely used a period of circulatory arrest to reconstruct the PAs and form the anastomosis. I think it is our philosophy that we just want to make sure we get the PAs as good as we 
possibly can and get the best possible view and get them to their maximum size.

Dr Emile A. Bacha (Boston, Mass). I have a comment and a question.

Do you think the improved survival that you have shown is a matter of a learning curve? It seems to me over the last few years that you have been using a right-sided conduit and before that you were using a left-sided conduit.

Dr Barron. Yes, there is no doubt that because the design is a retrospective study with a historical control, it could well be. What we could say is that we saw an immediate improvement in our survival figures when we undertook the left RV-PA conduit. Therefore that was early evidence that the hemodynamic benefit was there straightaway and maybe there was not too much of a learning curve.

Dr Bacha. The reason I am asking is that we also in Boston mostly are doing a right-sided RV-PA conduit, and we have not seen a change in survival, but we have definitely seen the greater facility at stage II.
The comment I was going to make is that this conduit crossing from the left to the right underneath the sternum can be troublesome sometimes in a stage II procedure. We have 2 patients who had their stage I procedures at our institution and went on to have a stage II procedure at another institution who both died at the time of the redo operation when the surgeon sawed into the conduit, and it is a difficult situation, and in a small baby, to rescue these kids.

Dr Vaughn A. Starnes (Los Angeles, Calif). I have 1 quick question. Did you notice a differential in time between when you did your stage II procedure, in left versus right, as an indicator of quality of shunt?

Dr Barron. No, there is no difference in time. Our mean time is 22 weeks. What we have found is that we do the stage II procedure in the entire RV-PA conduit group slightly earlier than we were doing it in the classical Norwood procedure group. I think that is partly because we were anxious to see the anatomy early on when we started the procedure, and it has just kind of stuck with us. 